\title{
Comparison of the Diagnostic Accuracy of the MSLN Gene Products, Mesothelin and Megakaryocyte Potentiating Factor, as Biomarkers for Mesothelioma in Pleural Effusions and Serum
}

\author{
Jenette Creaney, ${ }^{1}$ Sophie Sneddon, ${ }^{2}$ Ian M. Dick, ${ }^{2}$ Hanne Dare, ${ }^{1}$ Neil Boudville, ${ }^{3}$ \\ Arthur William Musk, ${ }^{4}$ Steven J. Skates, ${ }^{5}$ and Bruce W. S. Robinson ${ }^{6}$ \\ ${ }^{1}$ National Centre for Asbestos Related Diseases, School of Medicine and Pharmacology, University of Western Australia and \\ Australian Mesothelioma Tissue Bank, Sir Charles Gairdner Hospital, Perth, WA 6009, Australia \\ ${ }^{2}$ National Centre for Asbestos Related Diseases, School of Medicine and Pharmacology, University of Western Australia, \\ Sir Charles Gairdner Hospital, Perth, WA 6009, Australia \\ ${ }^{3}$ University of Western Australia, School of Medicine and Pharmacology, and Sir Charles Gairdner Hospital, \\ Department of Renal Medicine, Verdun Street, Nedlands, WA 6009, Australia \\ ${ }^{4}$ School of Population Health, University of Western Australia and Department of Respiratory Medicine, \\ Sir Charles Gairdner Hospital, Perth, WA 6009, Australia \\ ${ }^{5}$ Biostatistics Center, Massachusetts General Hospital, 50 Staniford Street, Suite 560, Boston, MA 02114-2521, USA \\ ${ }^{6}$ National Centre for Asbestos Related Diseases, School of Medicine and Pharmacology, University of Western Australia and \\ Department of Respiratory Medicine, Sir Charles Gairdner Hospital, Perth, WA 6009, Australia
}

Correspondence should be addressed to Jenette Creaney; jenette.creaney@uwa.edu.au

Received 11 June 2013; Accepted 13 July 2013

Academic Editor: Irene Rebelo

Copyright (C) 2013 Jenette Creaney et al. This is an open access article distributed under the Creative Commons Attribution License, which permits unrestricted use, distribution, and reproduction in any medium, provided the original work is properly cited.

The MSLN gene products, soluble mesothelin and megakaryocyte potentiating factor (MPF), are being investigated as biomarkers for the asbestos-related cancer malignant mesothelioma (MM). Pleural fluid biomarkers of MM can be elevated when serum levels remain normal. The aim of this study was to determine if this was true for MPF and to compare levels of mesothelin. Biomarker concentrations were compared in $66 \mathrm{MM}$ patients, 39 patients with other malignancies, 37 with benign disease, 18 asbestos-exposed healthy individuals, and 53 patients with chronic kidney disease. In pleural effusions, MPF and soluble mesothelin concentrations were both significantly elevated in MM patients relative to controls. No significant difference between the area under the receiver operator curve (AUC) for MPF $(0.945 \pm 0.02)$ and mesothelin $(0.928 \pm 0.03)$ when distinguishing MM from all other causes of effusion was observed. MPF and mesothelin serum concentrations were highly correlated and of equivalent diagnostic accuracy with AUCs of $0.813 \pm 0.04$ and $0.829 \pm 0.03$, respectively. Serum levels of both markers increased with decreasing kidney function. In conclusion, MPF is elevated in the pleural effusions of MM patients similar to that of mesothelin. Mesothelin and MPF convey equivalent diagnostic information for distinguishing MM from other diseases in pleural effusions as well as serum.

\section{Introduction}

Malignant mesothelioma (MM) is an aggressive asbestosinduced cancer affecting the mesothelial cells lining the serosal cavities of the body including the pleura and peritoneum. The median survival is generally less than one year $[1,2]$. The study of MM-specific biomarkers is being undertaken in order to improve diagnosis, assessment of disease progression, and response to treatment. Mesothelin family proteins in particular have been identified as likely biomarkers for this disease, particularly in a diagnostic setting.

The MSLN gene is located on chromosome 16p13.3 and encodes at least four protein products: megakaryocyte potentiating factor (MPF) $[3,4]$ and three isoforms of mesothelin: variant 1 (mesothelin) [5], the as yet uncharacterised, variant $2[5,6]$, and variant 3 (soluble-mesothelin-related protein (SMRP)) [7]. 
TABLE 1: Comparison of antibody-based assay results for megakaryocyte potentiating factor.

\begin{tabular}{|c|c|c|c|c|c|c|}
\hline \multirow[b]{2}{*}{ Report } & \multirow[b]{2}{*}{ Manufacturer of assay } & \multirow[b]{2}{*}{ Antibodies used } & \multirow[b]{2}{*}{ Sensitivity for MM } & \multicolumn{3}{|c|}{ Specificity } \\
\hline & & & & $\begin{array}{l}\text { cf benign and } \\
\text { controls }\end{array}$ & cf malignancy & Overall \\
\hline Onda et al., 2006 [12] & Authors & MPF25 and MPF49 & $51 / 56(91 \%)$ & $0 / 70$ & - & $100 \%$ \\
\hline Shiomi et al., 2006 $[13]$ & Authors & 7E7 and PoAb-282 & $7 / 7$ & $0 / 13$ & $0 / 3$ & $100 \%$ \\
\hline Shiomi et al., 2008* [14] & Authors & 7E7 and PoAb-282 & $29 / 39(74 \%)$ & - & - & $87 \%(46 / 356)$ \\
\hline Shiomi et al., $2008^{*}[14]$ & Authors & 7E7 and 16K16 & $28 / 39(72 \%)$ & - & - & $96 \%(14 / 356)$ \\
\hline Creaney et al., 2008 [11] & IBL, Japan & 7E7 and PoAb-282 & $21 / 66(32 \%)$ & $3 / 70$ & $2 / 30$ & $95 \%$ \\
\hline Iwahori et al., 2008 [15] & Authors & $20-10$ and $41-28$ & 20/27 (74\%) & $1 / 47$ & $14 / 82$ & $88 \%$ \\
\hline Hollevoet et al., 2010 [16] & MBL, Japan & 20-10 and 41-28 & $58 / 85(68 \%)$ & $10 / 359$ & $3 / 63$ & $97 \%$ \\
\hline
\end{tabular}

*Values extrapolated from the presented data.

IBL: Immuno-Biologic Laboratories (Gunma, Japan).

MBL: Medical \& Biological Laboratories (Nagano, Japan).

MPF is a $31 \mathrm{kDa}$ secreted cytokine-like protein which has been shown to stimulate colony formation of mouse bone marrow cells in the presence of interleukin $3[3,4]$. The three mesothelin isoforms share a common $\mathrm{N}$-terminal region. Mesothelin is a glycophosphatidylinositol-(GPI-) linked cellsurface glycoprotein of approximately $40 \mathrm{kDa}$ and considered a differentiation molecule of the mesothelium [5]. Mesothelin can be cleaved or shed from the cell surface $[8,9]$. SMRP lacks the GPI-anchor region responsible for cell surface attachment and has a unique $\mathrm{C}$-terminal hydrophilic tail that may make the protein soluble [7].

There is in general good correlation between laboratories for the sensitivity and specificity of mesothelin to differentiate $\mathrm{MM}$ from benign conditions and other malignancies (reviewed in [10]); however there is disparity on the sensitivity of MPF in this setting with, at high specificities, sensitivities ranging from $32 \%$ [11] to over $90 \%[12,13]$ (Table 1), perhaps due to the use of different antibody clones in the four different reported MPF ELISA-based assays.

Pleural effusion MPF levels should logically provide more sensitive information than serum, given the close relationship between the fluid and the tumour. Mesothelin levels were elevated in the effusions of $15 \%$ of MM patients with normal serum levels [17]. Effusion MPF levels are likely to be clinically important but have not been reported to date; therefore the primary aim of this study was to address this question.

Recent studies using the commercialized assay of Iwahori and colleagues [15] have found that serum mesothelin and MPF are highly correlated and have an equivalent diagnostic accuracy for MM $[16,18]$. Both biomarkers were similarly affected by covariates such as age, kidney function, and body mass index as assessed in controls and by tumour stage and kidney function in MM patients $[19,20]$. Although the statistical significance was unclear, MPF was twice as sensitive as serum mesothelin for stage I MM [20] when compared at the specificity of $95 \%$ in control subjects. The authors thus recommended that further research in a large cohort be undertaken, and so the secondary aim of the current study was to evaluate MPF in a setting for MM diagnosis and compare the results obtained with two commercially produced assays and with soluble mesothelin in a large cohort of patients.

\section{Materials and Methods}

2.1. Patients. Serum and pleural effusion samples were collected from patients who attended Sir Charles Gairdner Hospital, Royal Perth Hospital, or the Hollywood Specialist Centre in Perth, Western Australia. All patients provided written informed consent. The study was approved by the human research ethics committees of the three hospitals. The diagnosis was confirmed by pathologists experienced in the diagnosis of MM, lung cancer, and effusion cytology. The diagnosis of pleural plaques and asbestosis was based on accepted radiological and clinical criteria [21-23]. Nonmalignant effusions were classified as exudates or transudates on the basis of Light's criteria [24]. Effusions were classified as being infection associated if microorganisms were detected in the fluid along with inflammatory cells or if the patient had pneumonia adjacent to the effusion. Clinical followup was until death or for a median of 20 (range 1-167) months to confirm that the clinical pattern of the illness matched the diagnosis. To assess biomarkers in pleural fluid, samples from $43 \mathrm{MM}$ patients were examined: 28 with epitheliod histology, 2 with biphasic, and 13 with histological data unavailable because diagnosis was made based upon clinical, radiological, and cytological evidence. For comparison, effusion samples from a group of 79 patients with non-MM malignant effusions and 143 with Nonmalignant effusions were examined (Table 2).

MPF concentrations determined using the Human NERC/mesothelin assay from Immuno-Biological Laboratories (IBL) were reported in a series of MM and control patients previously [11]. To assess the diagnostic accuracy of the Medical \& Biological Laboratories (MBL) Molecular MPF assay, the results of the two assays were compared in a subset of the samples previously reported on. The sample set consisted of $66 \mathrm{MM}$ patients: 32 were epitheliod, 3 biphasic, and 9 sarcomatoid; no histological data was available for further 22 patients who were diagnosed on clinical, radiological, and cytological evidence. The other asbestos-related disease (ARD) patients consisted of a mixture of asbestosis $(n=3)$, pleural plaques $(n=2)$, and a mixture of asbestosis and pleural plaques $(n=9)$. The group of patients designated Cancer Other consisted of breast $(n=3)$, melanoma $(n=2)$, 
TAble 2: Patient demographics and effusion mesothelin and MPF concentrations in MM patients and controls.

\begin{tabular}{|c|c|c|c|c|}
\hline Group & $\begin{array}{c}\text { Number of cases } \\
\text { (number of females) }\end{array}$ & $\begin{array}{c}\text { Mean age, years } \\
\text { (range) }\end{array}$ & $\begin{array}{l}\text { Effusion mesothelin } \\
(\mathrm{nM})^{\mathrm{a}, \mathrm{c}}\end{array}$ & $\begin{array}{c}\text { Effusion MPF } \\
(\mathrm{ng} / \mathrm{mL})^{\mathrm{a}, \mathrm{b}, \mathrm{c}}\end{array}$ \\
\hline MM & $43(6)$ & $71(42-88)$ & $35.1 \pm 7.2$ & $1464 \pm 219$ \\
\hline Non-MM malignant effusions & $79(47)$ & $70(37-96)$ & $7.1 \pm 0.7^{* * *}$ & $210 \pm 23^{* * *}$ \\
\hline Lung cancer & $42(17)$ & $72(48-92)$ & $6.4 \pm 0.9^{* * *}$ & $198 \pm 25^{* * *}$ \\
\hline Breast cancer & $19(19)$ & $65(37-96)$ & $5.8 \pm 0.8^{* * *}$ & $201 \pm 32^{* * *}$ \\
\hline Ovarian cancer & $11(11)$ & $66(42-86)$ & $12.2 \pm 4.1^{\mathrm{ns}}$ & $188 \pm 93^{* * *}$ \\
\hline Pancreatic cancer & $7(0)$ & $64(56-75)$ & $9.9 \pm 2.6^{\mathrm{ns}}$ & $420 \pm 147^{* *}$ \\
\hline Benign effusions & $143(39)$ & $66(19-96)$ & $2.7 \pm 0.8^{* * *}$ & $96 \pm 10^{* * *}$ \\
\hline ARD & $16(1)$ & $74(50-91)$ & $5.5 \pm 0.8^{* * *}$ & $170 \pm 20^{* * *}$ \\
\hline Exudate & $51(12)$ & $65(19-94)$ & $2.9 \pm 0.4^{* * *}$ & $107 \pm 14^{* * *}$ \\
\hline Infection & $42(10)$ & $64(30-96)$ & $2.0 \pm 0.3^{* * *}$ & $48 \pm 13^{* * *}$ \\
\hline Transudate & $34(16)$ & $71(12-93)$ & $4.0 \pm 0.6^{* * *}$ & $148 \pm 14^{* * *}$ \\
\hline
\end{tabular}

a exponentiated mean of log transformed data plus/minus standard error of $\log$ transformed data $* 100$.

${ }^{\mathrm{b}}$ MPF concentrations determined from Human MPF Assay (MBL).

${ }^{c}$ significant difference between indicated cohorts and mesothelioma group as a whole $(n=43)$ as determined by Student's $t$-test (ns is not significant; ${ }^{* *}$ is $P<0.001$; and ${ }^{* * *}$ is $\left.P<0.0001\right)$.

TABLE 3: Patient demographics and serum mesothelin and MPF concentrations in MM patients and controls.

\begin{tabular}{|c|c|c|c|c|c|}
\hline Group & $\begin{array}{c}\text { Number of cases } \\
\text { (females) }\end{array}$ & $\begin{array}{c}\text { Mean age, years } \\
\text { (range) }\end{array}$ & $\begin{array}{c}\text { Serum mesothelin } \\
(\mathrm{nM})^{\mathrm{a}, \mathrm{d}}\end{array}$ & $\begin{array}{c}\text { Serum N-ERC } \\
(\mathrm{MPF})(\mathrm{ng} / \mathrm{mL})^{\mathrm{a}, \mathrm{b}, \mathrm{d}}\end{array}$ & $\begin{array}{l}\text { Serum MPF } \\
(\mathrm{ng} / \mathrm{mL})^{\mathrm{a}, \mathrm{c}, \mathrm{d}}\end{array}$ \\
\hline $\mathrm{MM}$ & $66(5)$ & $66(48-84)$ & $4.29 \pm 0.7$ & $0.16 \pm 0.05$ & $40.37 \pm 6.1$ \\
\hline Cancer lung & $19(7)$ & $72(58-82)$ & $1.77 \pm 0.4^{* *}$ & $0.23 \pm 0.1^{* *}$ & $15.13 \pm 3.4^{* *}$ \\
\hline Cancer other & $10(5)$ & $73(50-82)$ & $0.87 \pm 0.3^{* * *}$ & $0.58 \pm 0.19^{* * *}$ & $13.07 \pm 2.3^{* *}$ \\
\hline Asbestos exposed & $18(8)$ & $61(37-86)$ & $0.41 \pm 0.1^{* * *}$ & $0.04 \pm 0.02^{* * *}$ & $9.66 \pm 1.6^{* * *}$ \\
\hline $\mathrm{ARD}$ & $14(1)$ & $73(60-82)$ & $1.07 \pm 0.1^{* * *}$ & $0.10 \pm 0.06^{* * *}$ & $12.19 \pm 2.3^{* * *}$ \\
\hline PE-benign & $23(7)$ & $68(32-86)$ & $0.70 \pm 0.2^{* * *}$ & $0.07 \pm 0.3^{* * *}$ & $9.53 \pm 1.2^{* * *}$ \\
\hline
\end{tabular}

a exponentiated mean of log transformed data plus/minus standard error of log transformed data $* 100$.

${ }^{b}$ MPF concentrations determined from Human N-ERC/Mesothelin Assay (IBL).

${ }^{\mathrm{c}} \mathrm{MPF}$ concentrations determined from Human MPF Assay (MBL).

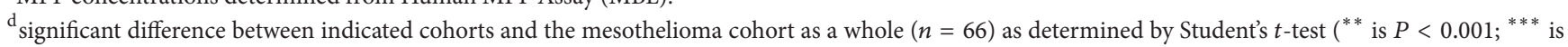
$P<0.0001)$.

pancreatic $(n=2)$ and one each of lymphoma, melanoma, and thyroid cancers. The group of patients with benign pleural effusions consisted of exudates $(n=18)$, including 8 related to infection, and transudates $(n=5)$ (Table 3$)$.

Kidney function effects on MPF levels were determined on a subset of randomly selected samples previously assessed for serum mesothelin [25], with approximately 30 patients in each of the Stages II to V chronic kidney disease (CKD) [26]; none of the participants had a previous history of malignancy (Table 4).

2.2. Biomarker Assays. Soluble mesothelin concentrations were determined using the MESOMARK assay (Fujirebio Diagnostics, Malvern, PA, USA). MPF concentrations were determined using either the Human N-ERC/Mesothelin Assay kit (Immuno-Biological Laboratories (IBL), Gunma, Japan) or the Ab-Match ASSEMBLY Human MPF kit and Ab-Match UNIVERSAL kit (Medical \& Biological Laboratories (MBL), Nagano, Japan). Biomarker concentrations were performed in duplicate according to the manufacturers' protocols. Concentrations were determined from a standard curve performed on each plate. Dilution of samples was carried out if necessary using the diluent supplied by the manufacturer. The limit of detection (LOD) for the assays was reported to be $0.3 \mathrm{nM}$ for the MESOMARK, $0.024 \mathrm{ng} / \mathrm{mL}$ for N-ERC/Mesothelin, and $0.03 \mathrm{ng} / \mathrm{mL}$ for the MPF assay. For the purposes of data analysis, concentrations of samples below LOD were assigned the value of the respective LOD.

2.3. Statistical Analysis. Selection of random subsets of patients was performed using the random sampling function in Microsoft Excel (Redmond, WA, USA). Differences between groups of patients were assessed by Student's $t$-test on log scale values to normalize the distribution. A two-sided $P$ value $<0.05$ was accepted as significant. The area under the curve (AUC) of Receiver Operating Characteristic (ROC) curves was compared using the method of DeLong et al. [28] and results reported as AUC $\pm 95 \%$ confidence interval (CI). Spearman's correlation coefficient was used to assess correlations between different biomarkers. Statistical analysis was performed using GraphPad Prism (California, USA) and Medcalc software (Mariakerke Belgium). 
TABle 4: Patient demographics and serum creatinine, mesothelin, and MPF concentrations in patients with chronic kidney disease (CKD).

\begin{tabular}{|c|c|c|c|c|c|}
\hline CKD stage & $\begin{array}{l}\text { Number of cases } \\
\text { (number of females) }\end{array}$ & $\begin{array}{c}\text { Mean age, years } \\
\text { (range) }\end{array}$ & $\begin{array}{c}\text { Median eGFR }{ }^{\mathrm{a}} \\
\left(\mathrm{mL} / \mathrm{min} / 1.73 \mathrm{~m}^{2}\right) \\
(\text { range })\end{array}$ & $\begin{array}{l}\text { Serum mesothelin } \\
(\mathrm{nM})^{\mathrm{b}, \mathrm{d}}\end{array}$ & $\begin{array}{l}\text { Serum MPF } \\
(\mathrm{ng} / \mathrm{mL})^{\mathrm{b}, \mathrm{c}, \mathrm{d}}\end{array}$ \\
\hline II & $30(12)$ & $68(25-95)$ & $74(62-89)$ & $1.05 \pm 0.09$ & $16.5 \pm 1.8$ \\
\hline III & $32(16)$ & $68(42-91)$ & $40(30-59)$ & $1.4 \pm 0.15^{*}$ & $32.1 \pm 2.86^{* * *}$ \\
\hline IV & $30(12)$ & $64(32-96)$ & $22(16-28)$ & $2.4 \pm 0.19^{* * *}$ & $46.2 \pm 5.4^{* * *}$ \\
\hline $\mathrm{V}$ & $29(13)$ & $66(46-96)$ & $12(3-14)$ & $2.8 \pm 0.29^{* * *}$ & $53.6 \pm 7.6^{* * *}$ \\
\hline
\end{tabular}

a estimated glomerular filtration rate was calculated using the Modified Diet in Renal Disease (MDRD) Formula [27].

${ }^{\mathrm{b}}$ exponentiated mean of log transformed data plus/minus standard error of log transformed data $* 100$.

${ }^{c}$ MPF concentrations determined from Human MPF Assay (MBL).

d significant difference between indicated cohorts and the Stage II CKD patient group $(n=30)$ as determined by Student's $t$-test $\left({ }^{*}\right.$ is $P<0.05 ;{ }^{* * *}$ is $P<$ $0.0001)$.

\section{Results}

3.1. Pleural Effusion Biomarker Concentrations. As MPF has been reported to have cytokine-like functions and also suggested to be associated with thrombocytosis, MPF concentrations were examined in effusions from patients with inflammatory and infective conditions in addition to patients with non-MM malignancies.

The estimated median concentration of MPF in MM patients was $1464 \pm 219 \mathrm{ng} / \mathrm{mL}$ and was significantly higher than that in patients with benign effusions grouped together $(96 \pm 10 \mathrm{ng} / \mathrm{mL} ; P<0.0001)$ and also higher than that in all patients with other malignancies grouped together $(210 \pm$ $23 \mathrm{ng} / \mathrm{mL} ; P<0.0001$ ) (Table 2; Figure 1). There was no significant difference between the effusion MPF concentration in patients with benign effusions related to infection and those of other benign causes.

The estimated median concentration of effusion mesothelin in MM patients was $33 \pm 7.2 \mathrm{nM}$ and was significantly higher than that in patients with benign effusions grouped together $(3 \pm 0.8 \mathrm{nM} ; P<0.0001)$ and also higher than that in all patients with other malignancies grouped together $(7.1 \pm$ $0.7 \mathrm{nM} ; P<0.0001$ ) (Table 2; Figure 1). There was a significant correlation between effusion MPF and mesothelin results $(r=0.809 ; P<0.0001)$.

ROC curves were generated to assess the ability of the effusion markers to distinguish between patients with MM from all the other patients $(n=265)$. The AUC $(95 \% \mathrm{CI})$ of MPF was 0.945 (0.923-0.977), not significantly different from that of mesothelin (0.928; $(0.890-0.956)$ ) (Figure 1). At a specificity of $95 \%$ relative to healthy or patients with benign disease $(n=55)$, sensitivity of effusion MPF was $81 \%$ (threshold $=600 \mathrm{ng} / \mathrm{mL}$ ) and that of mesothelin was $70 \%$ (threshold $=20 \mathrm{nM}$ ).

3.2. Serum MPF. Serum MPF was measured using two different commercial assays. Using the N-ERC assay (IBL) $\mathrm{N}$-ERC/MPF concentrations in the serum of patients with $\mathrm{MM}$ ranged from undetectable to $5.9 \mathrm{ng} / \mathrm{mL}$. The estimated median concentration of $\mathrm{N}-\mathrm{ERC} / \mathrm{MPF}$ in $\mathrm{MM}$ patients was $0.16 \pm 0.05 \mathrm{ng} / \mathrm{mL}$ and was not significantly different from that in the healthy individuals and patients with benign conditions grouped together $(0.06 \pm 0.02 \mathrm{ng} / \mathrm{mL})$ nor was it different from that in all patients with other malignancies grouped together $(0.34 \pm 0.1 \mathrm{ng} / \mathrm{mL})$ (Figure 2$)$.

In the same sample set, using the MPF assay (MBL), MPF concentrations in the serum of MM patients ranged from 2.6 to $622 \mathrm{ng} / \mathrm{mL}$ and were several orders of magnitude higher than those observed with the IBL assay. The mean concentration of MPF in MM patients was $40.4 \pm 6.1 \mathrm{ng} / \mathrm{mL}$ and was significantly higher than that in the healthy individuals and patients with benign conditions grouped together (Figure 2). There was a significant but weak correlation between the results of the MPF assays $(r=0.263 ; P<0.001)$ (Figure 2$)$.

3.3. Serum Mesothelin and MPF. Serum mesothelin was measured using the MESOMARK assay. Concentrations in the serum of patients with MM ranged from undetectable to $85 \mathrm{nM}$. The mean concentration of mesothelin in $\mathrm{MM}$ patients was $4.3 \pm 0.7 \mathrm{nM}$ and was significantly higher than that in patients with other malignancies grouped together $(1.39 \pm 0.3 \mathrm{nM} ; P<0.0001)$ and also higher than that in the patients with benign conditions and healthy individuals grouped together $(0.66 \pm 0.1 \mathrm{nM} ; P<0.0001)$ (Figure 2). There was a significant correlation between MPF (MBL assay) and mesothelin results in these patients $(r=0.706 ; P<$ 0.0001) (Figure 2).

ROC curves were generated to assess the ability of the markers to distinguish between patients with MM from all the other cases in this study set $(n=150)$. The AUC for the $\mathrm{N}$-ERC/MPF was 0.549 (0.465-0.630), for the MPF was 0.813 (0.741-0.872), and for mesothelin was 0.829 (0.759-0.886) (Figure 2). The AUC for N-ERC/MPF was significantly less than that for MPF and for mesothelin $(P<0.0001)$. There was no difference in the AUC for serum MPF and for mesothelin in this patient set $(P=0.623)$.

At a specificity of $95 \%$ relative to healthy or patients with benign disease $(n=55)$, sensitivity of serum N-ERC was $29 \%$ (threshold $=1.6 \mathrm{ng} / \mathrm{mL}$ ), of serum MPF was 52\% (threshold = $33.2 \mathrm{ng} / \mathrm{mL}$ ), and of serum mesothelin was $61 \%$ (threshold $=$ $2.4 \mathrm{nM})$.

3.4. Kidney Function and Serum Biomarker Values. Serum mesothelin levels increased with decreasing kidney function, as previously reported [25] (Figure 3). In these patients, serum MPF concentrations increased with diminishing renal 


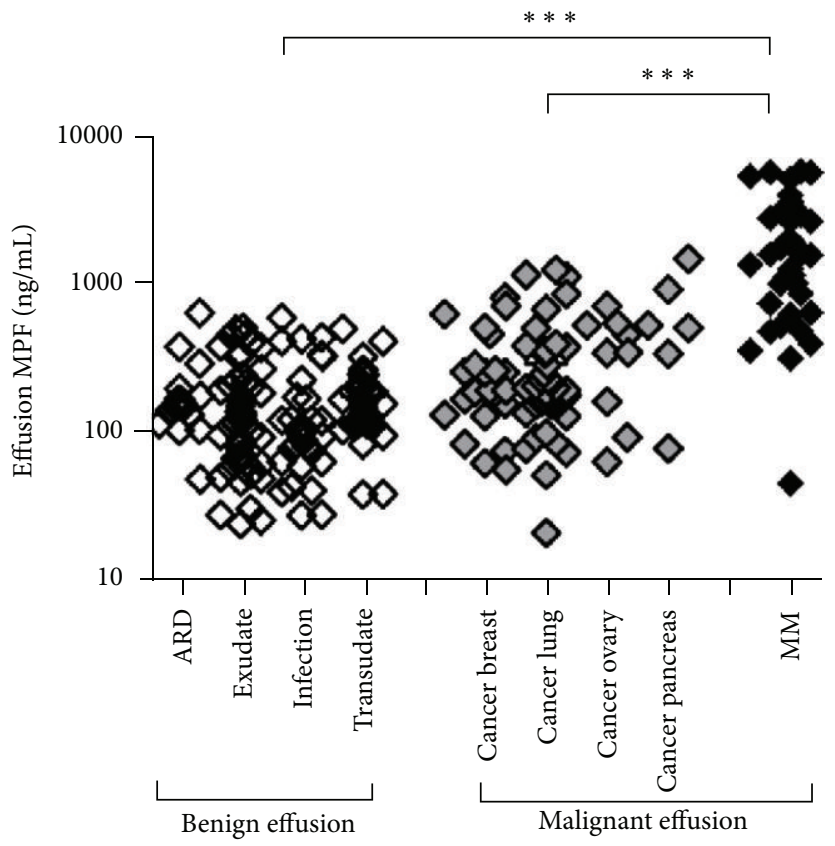

(a)

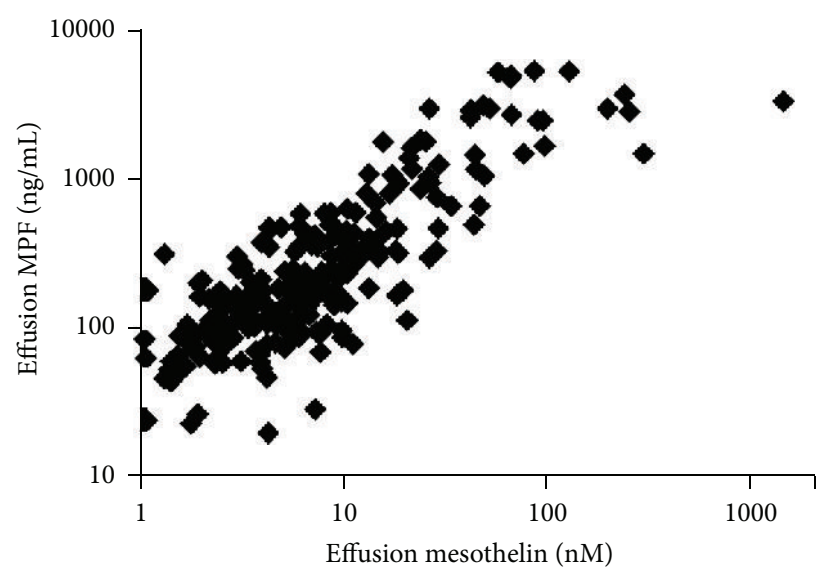

(c)

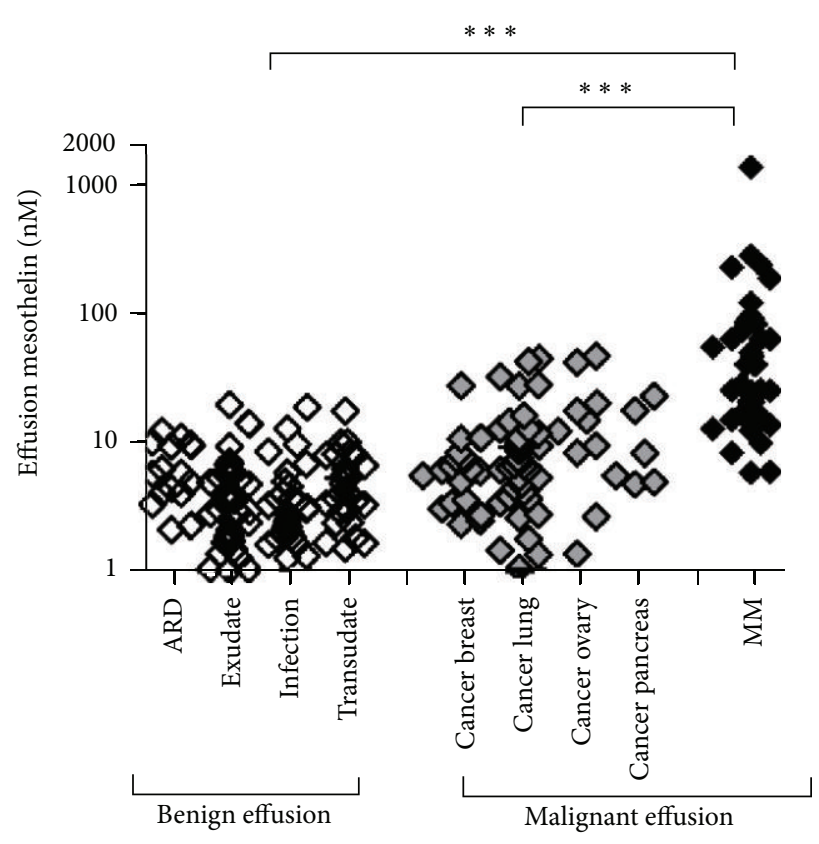

(b)

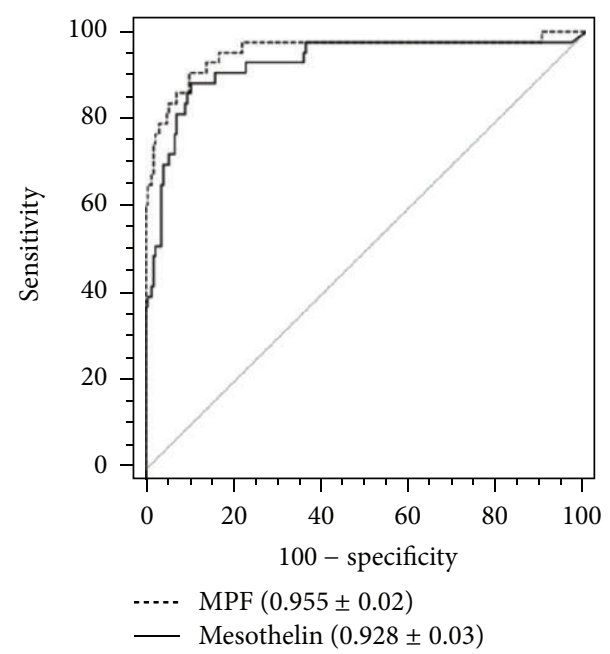

(d)

FIGURE 1: Biomarker concentrations in pleural effusions: (a) MPF as determined using assay from MBL; (b) soluble mesothelin concentrations; (c) correlation between MPF concentrations determined by MBL assays and mesothelin; and (d) Receiver Operating Characteristic (ROC) curves showing accuracy of effusion biomarkers in differentiating all patients with MM $(n=43)$ from all other cases $(n=222)$. (Significant difference between indicated cohorts: ${ }^{* * *} P<0.0001$.)

function (range 4.5 to $173 \mathrm{ng} / \mathrm{mL}$ ) (Figure 3). The group mean MPF level for patients with Stage II kidney disease $(16.5 \pm 1.8 \mathrm{ng} / \mathrm{mL})$ was significantly lower than that for patients with Stages III, IV, and V $(P<0.001)$. There was a strong correlation between mesothelin and MPF concentrations in these samples $(r=0.731 ; P<0.0001)$. Patient age, sex, smoking, asbestos exposure, or diabetes were not associated with MPF concentration. Of the 121 samples from patients with CKD Stages II-V in this study, $70(58 \%)$ were found to have MPF concentration greater than $30 \mathrm{ng} / \mathrm{mL}$.

\section{Discussion}

The main products of the MSLN gene on chromosome 16p13.3, mesothelin and MPF, are elevated in the serum of MM patients. This study demonstrated that MPF is also elevated in the pleural effusions of MM patients and that there is strong correlation between the two markers. There was no difference in the diagnostic accuracy for MM in this study between soluble mesothelin and MPF.

The choice of antibody pair in ELISA can influence the accuracy of a test. Previous studies using assays based 


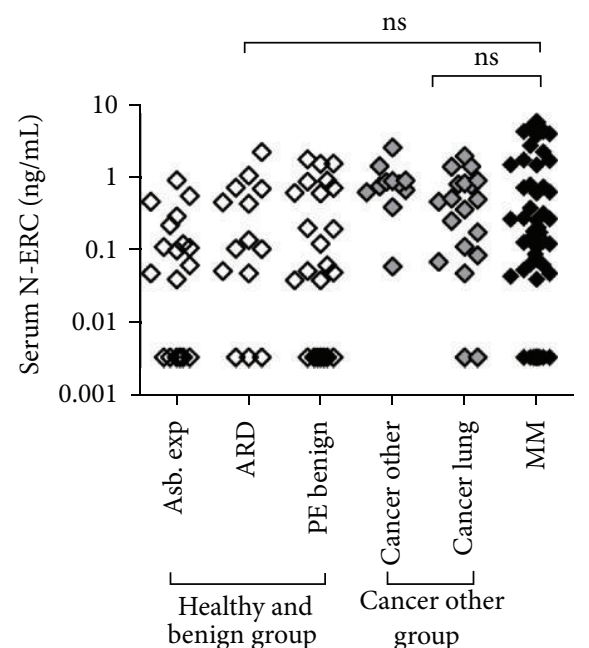

(a)

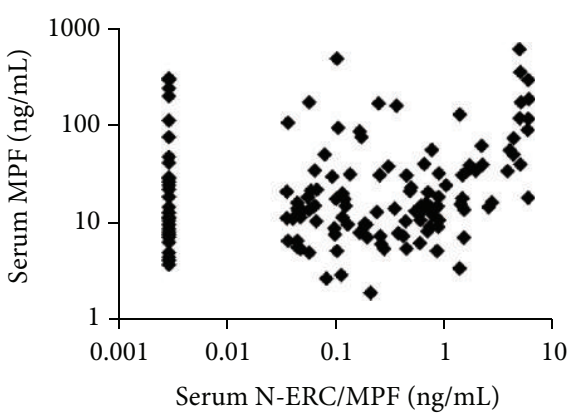

(c)

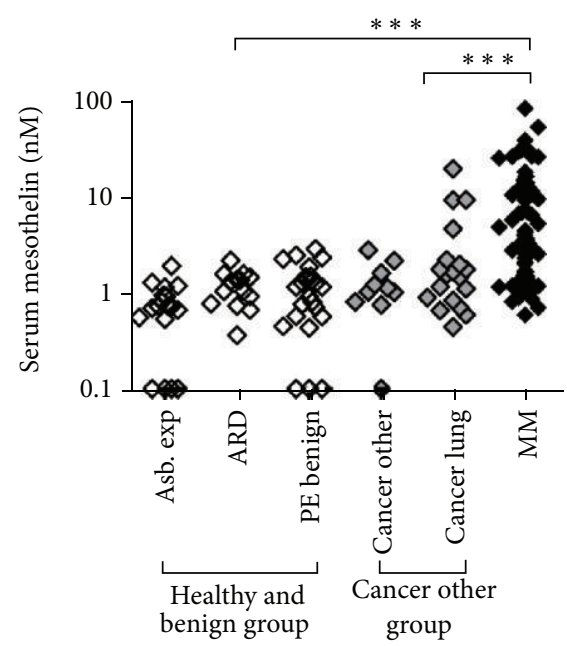

(e)

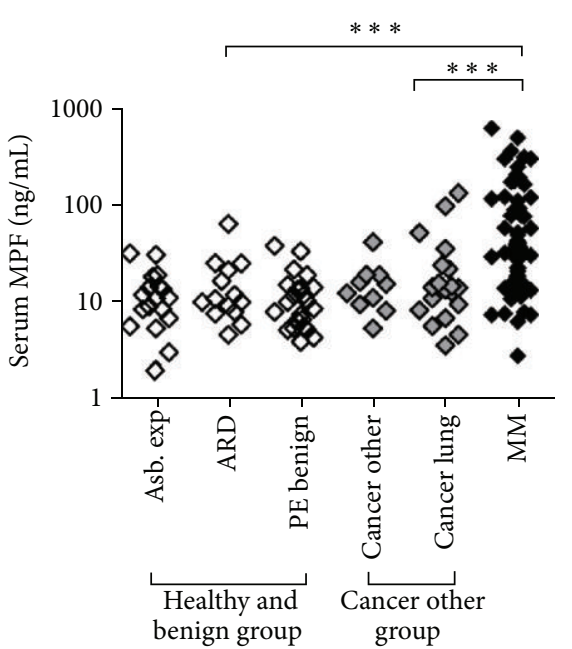

(b)

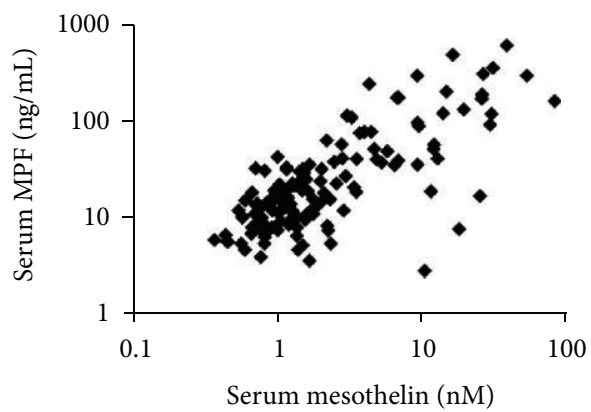

(d)

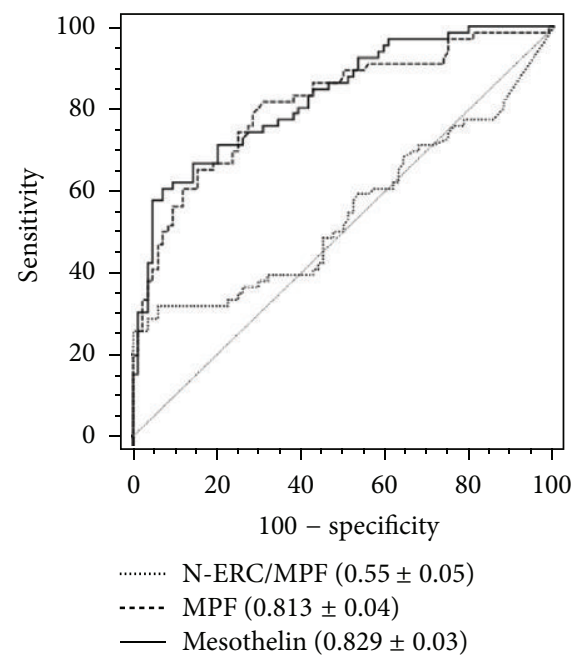

(f)

FIGURE 2: Biomarker concentrations in serum: biomarker concentrations were determined at least in duplicate by ELISA and individual patient values plotted. (a) MPF as determined using N-ERC assay from IBL; (b) MPF as determined using assay from MBL; (c) correlation between MPF concentrations determined by the two different independent assays; (d) correlation between MPF concentrations determined by MBL assays and mesothelin; (e) soluble mesothelin concentrations; and (f) Receiver Operating Characteristic (ROC) curves showing accuracy of serum biomarkers in differentiating all patients with MM $(n=66)$ from all other cases $(n=84)$. (Significant difference between indicated cohorts: $\mathrm{ns}$ is not significant; ${ }^{* * *} P<0.0001$.) 


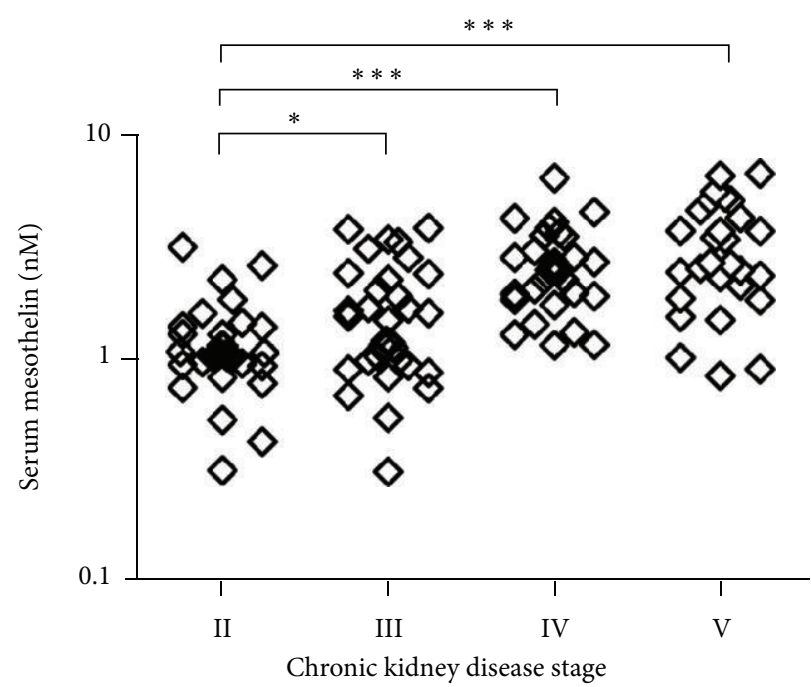

(a)

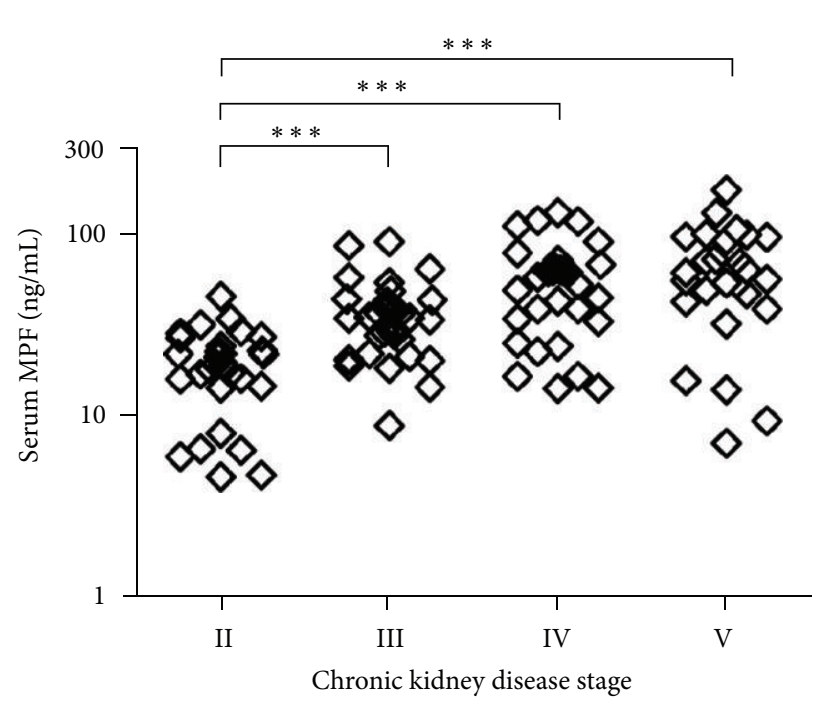

(b)

FIGURE 3: Biomarker concentrations in serum of patients with chronic kidney disease: (a) soluble mesothelin concentrations and (b) MPF concentrations as determined using assay from MBL. (Significant difference between indicated cohorts: ${ }^{*} P<0.05 ;{ }^{* * *} P<0.0001$.)

on four different anti-MPF antibody pairs have generally reported favourable results for MPF as an MM biomarker (Table 1) [12,14-16]. The current study directly compared two of these assays and found that the assay using the antibodies 20-10 and 41-28 (as developed by [15] and manufactured by $\mathrm{MBL}$ ) was superior to the other assay examined with comparable diagnostic accuracy and clinical performance to that of mesothelin, the most well characterised biomarker for MM.

The previous inconsistent results regarding the diagnostic accuracy of serum MPF as a marker for MM, where several studies found greater than $90 \%$ sensitivity for $\mathrm{MM}$ at high specificity $[12,13]$, compared to one study reporting a sensitivity of $32 \%$ [11] are likely attributable to the use of different assays. To our knowledge the MPF assay utilising the antibody pair 7E7 and PoAb-282, as used in the latter study, is no longer commercially available. The current findings support a previous work that found serum MPF to be a viable biomarker for MM [16].

Over $70 \%$ of MM patients present with an effusion $[29,30]$, and such effusions provide specimens that can be used for diagnosis and clinical management decisions. This study has shown for the first time that MPF is elevated in the pleural fluid of MM patients. Based upon the fact that effusions in $\mathrm{MM}$ are in contact with the tumour and that mesothelin has previously been shown to be elevated in effusions $[17,31,32]$, this was an expected finding. However, some other MM-associated biomarkers, for example CA125 and osteopontin, are, in addition to being elevated in MM effusions, also elevated in various benign conditions thus limiting their clinical utility $[33,34]$. Given that MPF was originally identified because of its cytokine-like activity in vitro $[3,4]$, a function not previously associated with the related gene product mesothelin, it was considered important to examine the association between MPF concentrations in effusions and inflammatory conditions. In the current study MPF concentrations were of a similar magnitude in benign effusions related to infective or other causes. Any cytokineassociated function of MPF occurring in infective conditions did not affect the diagnostic utility of the marker for MM.

A strong correlation between MPF and mesothelin in serum was found in this study, consistent with previous studies [18]. There was no significant difference in the diagnostic accuracy of the two markers for MM, and both markers behaved in a very similar fashion in relation to changes in kidney function. Whilst little is known about the transcriptional and/or translational regulation of these two proteins, as both MPF and mesothelin are products of the MSLN gene [35], conceivably they could be produced in equimolar amounts by a cell, as reflected by the equivalence in serum levels.

Similarly, there was a strong correlation between effusion MPF and mesothelin concentrations, with no significant difference in their diagnostic accuracy for MM. This raises the possibility that the assays are measuring the same protein; however no cross-reactivity was observed between the antibodies and the standards of the MPF and mesothelin assay kits (data not shown). Why there is such concordance between the two proteins is difficult to envision given that cell-bound mesothelin must be cleaved or shed from the cell surface to be detected in solution. This cleavage must be tightly regulated to account for the strong correlation between mesothelin and MPF expressions. There is therefore the technical possibility that the MPF-mesothelin preprotein is not being cleaved (at the putative furin-cleavage site [35]) and that the approximately $70 \mathrm{kDa}$ molecule is being detected by both assays. This is currently under investigation.

In conclusion MPF is elevated in the pleural effusions of MM patients, and there is a strong correlation between 
mesothelin and MPF. Mesothelin and MPF convey equivalent diagnostic data in pleural effusions as well as serum and thus, in a clinical setting, could be used interchangeably.

\section{Conflict of Interests}

All of the authors declare no conflicting interests.

\section{Acknowledgments}

The samples used for this study form part of the Australian Mesothelioma Tissue Bank, a member bank of the Australasian Biospecimen Network, which is supported in part by the Australian National Health and Medical Research Council (NHMRC) (Grants 310670 and 628903). This study was supported in part by the NHMRC (Grant 1001020) and the Insurance Commission of WA. MPF standards and antibodies were kindly provided free of charge by Medical \& Biological Laboratories Co., Ltd, Japan. The authors would like to acknowledge all the participants in this study.

\section{References}

[1] B. W. S. Robinson, A. W. Musk, and R. A. Lake, "Malignant mesothelioma," Lancet, vol. 366, no. 9483, pp. 397-408, 2005.

[2] B. W. S. Robinson and R. A. Lake, "Advances in malignant mesothelioma," New England Journal of Medicine, vol. 353, no. 15, pp. 1591-1603, 2005.

[3] N. Yamaguchi, K. Hattori, M. Oh-Eda, T. Kojima, N. Imai, and N. Ochi, "A novel cytokine exhibiting megakaryocyte potentiating activity from a human pancreatic tumor cell line HPCY5,' Journal of Biological Chemistry, vol. 269, no. 2, pp. 805-808, 1994.

[4] T. Kojima, M. Oh-Eda, K. Hattori et al., "Molecular cloning and expression of megakaryocyte potentiating factor cDNA," Journal of Biological Chemistry, vol. 270, no. 37, pp. 21984-21990, 1995.

[5] K. Chang and I. Pastan, "Molecular cloning of mesothelin, a differentiation antigen present on mesothelium, mesotheliomas, and ovarian cancers," Proceedings of the National Academy of Sciences of the United States of America, vol. 93, no. 1, pp. 136$140,1996$.

[6] Z. E. Muminova, T. V. Strong, and D. R. Shaw, "Characterization of human mesothelin transcripts in ovarian and pancreatic cancer," BMC Cancer, vol. 4, article 19, 2004.

[7] N. Scholler, N. Fu, Y. Yang et al., "Soluble member(s) of the mesothelin/megakaryocyte potentiating factor family are detectable in sera from patients with ovarian carcinoma," Proceedings of the National Academy of Sciences of the United States of America, vol. 96, no. 20, pp. 11531-11536, 1999.

[8] I. Hellstrom, J. Raycraft, S. Kanan et al., "Mesothelin variant 1 is released from tumor cells as a diagnostic marker," Cancer Epidemiology Biomarkers and Prevention, vol. 15, no. 5, pp. 10141020, 2006.

[9] M. Ho, M. Onda, Q. C. Wang, R. Hassan, I. Pastan, and M. O. Lively, "Mesothelin is shed from tumor cells," Cancer Epidemiology Biomarkers and Prevention, vol. 15, no. 9, article 1751, 2006.

[10] J. Creaney and B. W. S. Robinson, "Serum and pleural fluid biomarkers for mesothelioma," Current Opinion in Pulmonary Medicine, vol. 15, no. 4, pp. 366-370, 2009.
[11] J. Creaney, D. Yeoman, Y. Demelker et al., "Comparison of osteopontin, megakaryocyte potentiating factor, and mesothelin proteins as markers in the serum of patients with malignant mesothelioma," Journal of Thoracic Oncology, vol. 3, no. 8, pp. 851-857, 2008.

[12] M. Onda, S. Nagata, M. Ho et al., "Megakaryocyte potentiation factor cleaved from mesothelin precursor is a useful tumor marker in the serum of patients with mesothelioma," Clinical Cancer Research, vol. 12, no. 14, pp. 4225-4231, 2006.

[13] K. Shiomi, H. Miyamoto, T. Segawa et al., "Novel ELISA system for detection of N-ERC/mesothelin in the sera of mesothelioma patients," Cancer Science, vol. 97, no. 9, pp. 928-932, 2006.

[14] K. Shiomi, Y. Hagiwara, K. Sonoue et al., "Sensitive and specific new enzyme-linked immunosorbent assay for N-ERC/ mesothelin increases its potential as a useful serum tumor marker for mesothelioma," Clinical Cancer Research, vol. 14, no. 5, pp. 1431-1437, 2008.

[15] K. Iwahori, T. Osaki, S. Serada et al., "Megakaryocyte potentiating factor as a tumor marker of malignant pleural mesothelioma: evaluation in comparison with mesothelin," Lung Cancer, vol. 62, no. 1, pp. 45-54, 2008.

[16] K. Hollevoet, K. Nackaerts, J. Thimpont et al., "Diagnostic performance of soluble mesothelin and megakaryocyte potentiating factor in mesothelioma," American Journal of Respiratory and Critical Care Medicine, vol. 181, no. 6, pp. 620-625, 2010.

[17] J. Creaney, D. Yeoman, L. K. Naumoff et al., "Soluble mesothelin in effusions: a useful tool for the diagnosis of malignant mesothelioma," Thorax, vol. 62, no. 7, pp. 569-576, 2007.

[18] K. Hollevoet, K. Nackaerts, R. Gosselin et al., "Soluble mesothelin, megakaryocyte potentiating factor, and osteopontin as markers of patient response and outcome in mesothelioma," Journal of Thoracic Oncology, vol. 6, no. 11, pp. 1930-1937, 2011.

[19] K. Hollevoet, J. Van Cleemput, J. Thimpont et al., "Serial measurements of mesothelioma serum biomarkers in asbestosexposed individuals: a prospective longitudinal cohort study," Journal of Thoracic Oncology, vol. 6, no. 5, pp. 889-895, 2011.

[20] K. Hollevoet, K. Nackaerts, O. Thas et al., "The effect of clinical covariates on the diagnostic and prognostic value of soluble mesothelin and megakaryocyte potentiating factor," Chest, vol. 141, no. 2, pp. 477-484, 2012.

[21] E. Kagan and A. Brody, "Immunopathology of asbestos-related lung disease," in Immunopathology of Lung Disease, R. Kradin and B. Robinson, Eds., pp. 421-444, Butterworth-Heinemann, Boston, Mass, USA, 1996.

[22] J. Spurzem and S. Rennard, "Immunopathology of idiopathic pulmonary fibrosis," in Immunopathology of Lung Disease, R. Kradin and B. Robinson, Eds., pp. 119-132, Butterworth-Heinemann, Boston, Mass, USA, 1996.

[23] B. Robinson, "Sarcoidosis," in Immunopathology of Lung Disease, R. Kradin and B. Robinson, Eds., pp. 165-190, Butterworth-Heinemann, Boston, Mass, USA, 1996.

[24] R. W. Light, M. I. Macgregor, P. C. Luchsinger, and W. C. Ball Jr., "Pleural effusions: the diagnostic separation of transudates and exudates," Annals of Internal Medicine, vol. 77, no. 4, pp. 507-513, 1972.

[25] N. Boudville, R. Paul, B. W. S. Robinson, and J. Creaney, "Mesothelin and kidney function-analysis of relationship and implications for mesothelioma screening," Lung Cancer, vol. 73, no. 3, pp. 320-324, 2011.

[26] A. S. Levey, J. Coresh, E. Balk, A. T. Kausz, A. Levin, and M. W. Steffes, "National Kidney Foundation practice guidelines for 
chronic kidney disease: evaluation, classification, and stratification," Annals of Internal Medicine, vol. 139, no. 2, pp. 137-147, 2003.

[27] A. S. Levey, J. P. Bosch, J. B. Lewis, T. Greene, N. Rogers, and D. Roth, "A more accurate method to estimate glomerular filtration rate from serum creatinine: a new prediction equation," Annals of Internal Medicine, vol. 130, no. 6, pp. 461-470, 1999.

[28] E. R. DeLong, D. M. DeLong, and D. L. Clarke-Pearson, "Comparing the areas under two or more correlated receiver operating characteristic curves: a nonparametric approach," Biometrics, vol. 44, no. 3, pp. 837-845, 1988.

[29] S. D. West and Y. C. G. Lee, "Management of malignant pleural mesothelioma," Clinics in Chest Medicine, vol. 27, no. 2, pp. 335354, 2006.

[30] A. Segal, G. F. Sterrett, F. A. Frost et al., "A diagnosis of malignant pleural mesothelioma can be made by effusion cytology: results of a 20 year audit," Pathology, vol. 45, no. 1, pp. 44-48, 2013.

[31] H. E. Davies, R. S. Sadler, S. Bielsa et al., "Clinical impact and reliability of pleural fluid mesothelin in undiagnosed pleural effusions," American Journal of Respiratory and Critical Care Medicine, vol. 180, no. 5, pp. 437-444, 2009.

[32] A. Scherpereel, B. Grigoriu, M. Conti et al., "Soluble mesothelin-related peptides in the diagnosis of malignant pleural mesothelioma," American Journal of Respiratory and Critical Care Medicine, vol. 173, no. 10, pp. 1155-1160, 2006.

[33] O. Topalak, U. Saygili, M. Soyturk et al., "Serum, pleural effusion, and ascites CA-125 levels in ovarian cancer and nonovarian benign and malignant diseases: a comparative study," Gynecologic Oncology, vol. 85, no. 1, pp. 108-113, 2002.

[34] B. D. Grigoriu, A. Scherpereel, P. Devos et al., "Utility of osteopontin and serum mesothelin in malignant pleural mesothelioma diagnosis and prognosis assessment," Clinical Cancer Research, vol. 13, no. 10, pp. 2928-2935, 2007.

[35] R. Hassan, T. Bera, and I. Pastan, "Mesothelin: a new target for immunotherapy," Clinical Cancer Research, vol. 10, no. 12 I, pp. 3937-3942, 2004. 


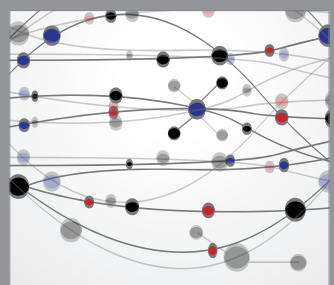

The Scientific World Journal
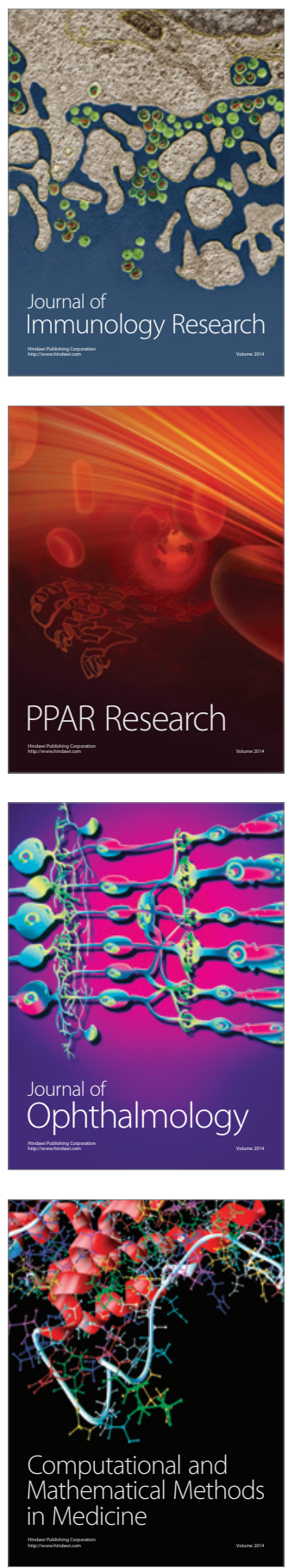

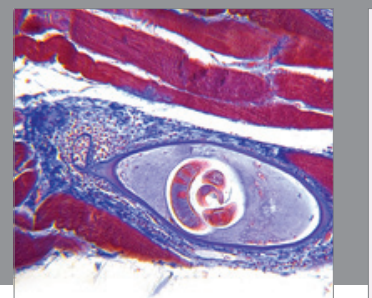

Gastroenterology

Research and Practice
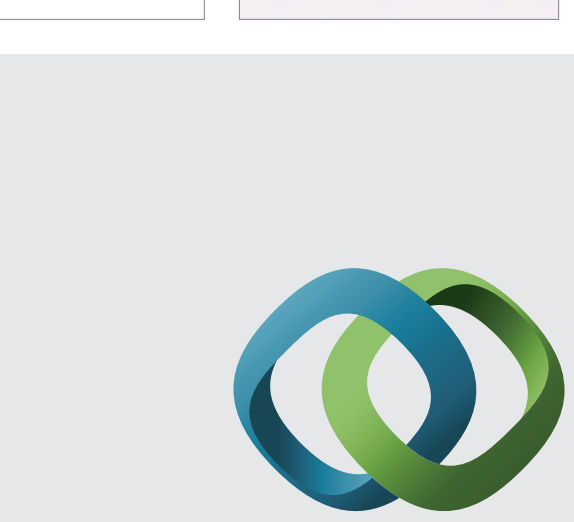

\section{Hindawi}

Submit your manuscripts at

http://www.hindawi.com
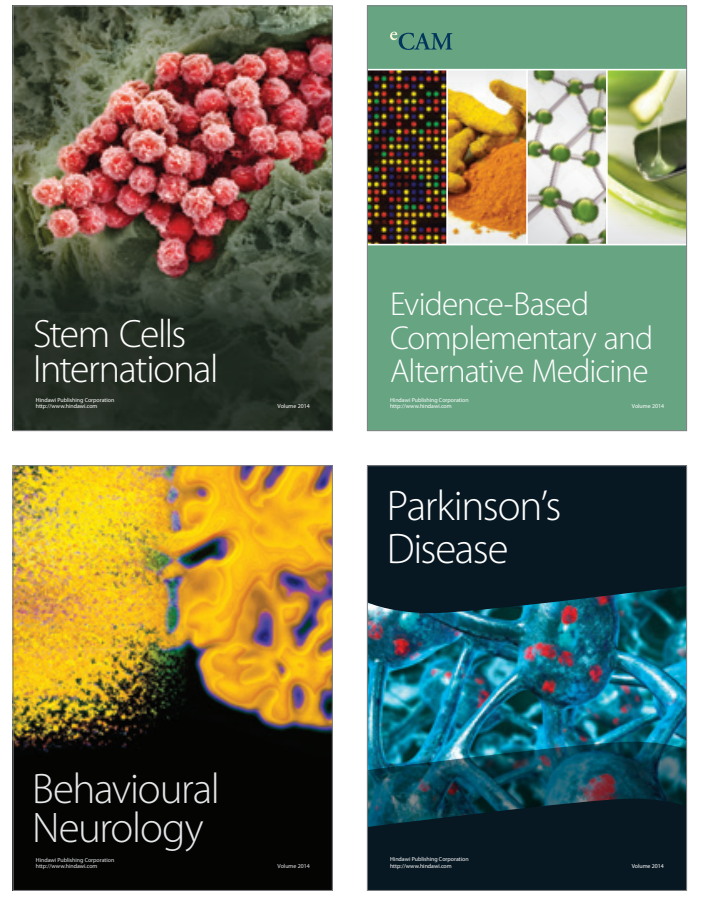
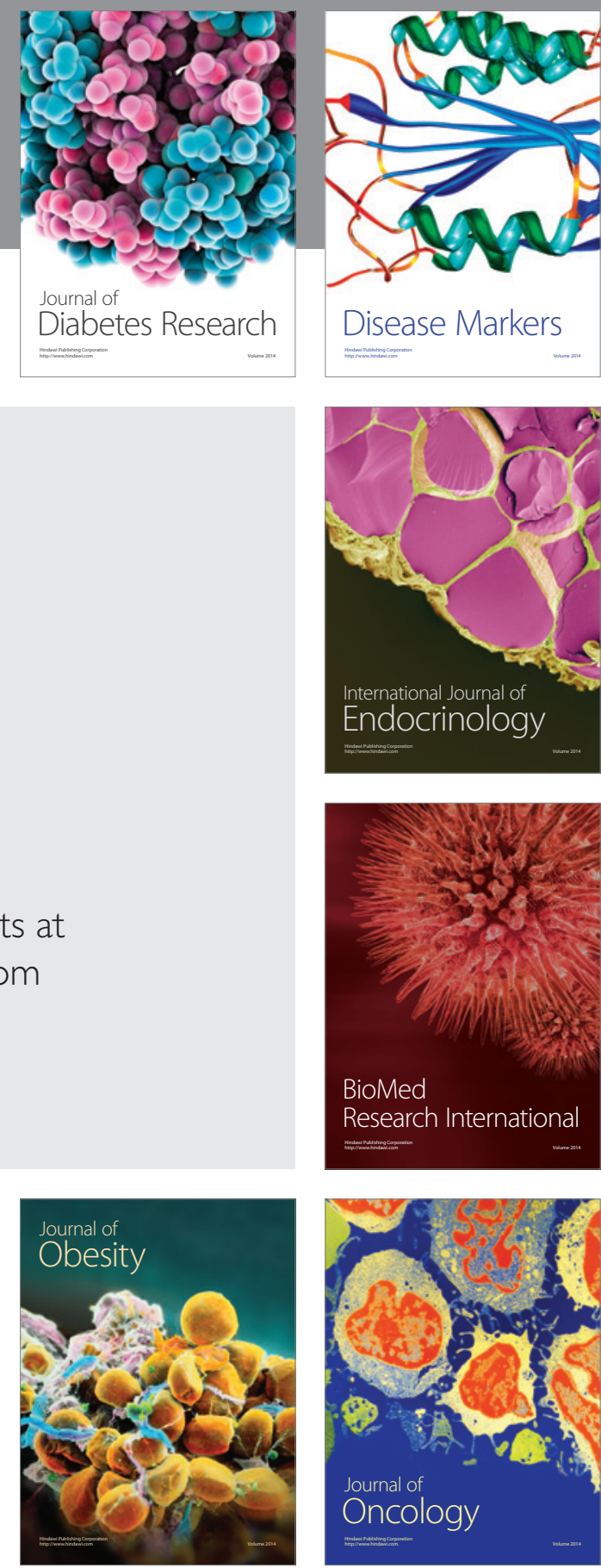

Disease Markers
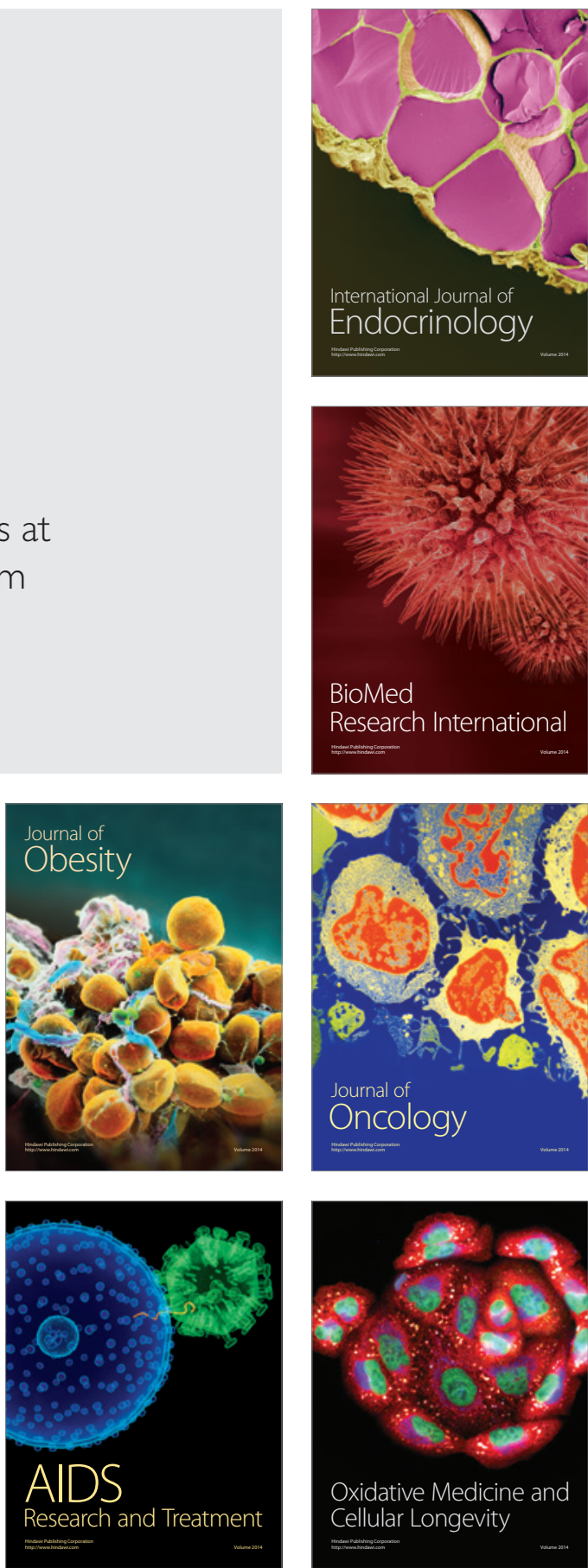